\begin{tabular}{c} 
International Journal of Engineering \& Technology, 7 (2.7) (2018) $441-443$ \\
International Journal of Engineering \& Technology \\
SPC \\
Website: www.sciencepubco.com/index.php/IJET \\
Research Paper \\
\hline
\end{tabular}

\title{
C Ran Towards 5g Networks in Virtual Environment
}

\author{
K.R.R Mohan, G Vennela*, M. Sai Kumar, Ch. Satya Srinivas, A. Harsha \\ Department of ECE, Koneru Lakshmaiah Education, Vaddeswaram, Guntur, Andhra Pradesh, India 522502 \\ *Corresponding author E-mail: vennelagudimella@gmail.com
}

\begin{abstract}
Cloud radio access network is an adaptable mobile network architecture with exponential development of portable traffic and the prerequisites of up and coming administrations are further pushing the cut-off points on current versatile systems; subsequently, overall research interests have moved toward 5G world that view which can address many challenges that mobile operators confront while attempting to support ever-growing end-user's needs towards 5th generation of mobile networks. Be that as it may, 5G systems are most certainly not to be sent until 2020; subsequently, there is a requirement for answers for address expanding requests of current systems, without acquiring colossal expenses on administrators. This paper proposes on-request organization of portable little cells, utilizing either client versatile handsets or remote radio units and non-aware power utilization of different hosts and virtual machines.
\end{abstract}

Keywords: Distributed Systems and Distributed applications, Non-Power aware, cloud computing, Real-time.

\section{Introduction}

The fifth age remote systems are quickly developing, yet Fifth Generation frameworks are just anticipated that would be sent by year 2020. In spite of the fact that, it is yet at some point till Fifth Generation models are solidified and confirmed, there is large acknowledgment in innovation drifts that definitely frame part of Fifth Generation worldview, and in addition the highlights and execution that must be bolstered. This segment draws a photo of what's in store from Fifth Generation, notwithstanding a short study of innovation patterns to be adopted. We don't guarantee that we are exhibiting an entire vision of Fifth Generation, but instead demonstrating how our proposed arrangement gives a minimal effort arrangement that can be based on existing advances of Fourth Generation, while proceeding to be important when the Fifth Generation frameworks are conveyed. Along these lines, versatile administrators would not be hesitant to receive such idea, which gives a stage towards conveying Fifth Generation administrations, without causing much expenses on non-applicable advances, particularly that the arrangement does not require high capital expenses nor broad organize arranging. Starting with the imagined condition of Fifth Generation, it is clear that portable traffic is developing at extraordinary rates what's more, will keep on growing. Traffic from remote and versatile gadgets are extrapolated to surpass that from wired gadgets by 2019. Notwithstanding traffic increment, 1000x throughput change is normal with 10 $\mathrm{Gb} / \mathrm{s}$ cell information rate. Client information rates are expected to rocket, achieving ten to hundred times that of current Fourth Generation. Dormancy is required to be decreased down to $1 \mathrm{~ms}$ endto-end. Every one of these improvements in execution must be combined with a colossal increment in number of cell phones, achieving hundred times the number of current associated gadgets. It is expected that the quantity of associated gadgets will be three times the worldwide populace in 2019. That colossal number of associated gadgets will accompany new progressed and various administrations, which the fifth generation organizing needs to help with the best quality of experience in light of the idea of the gadget and its usefulness. Fifth Generation systems need to help each one of those administrations, while keeping the costs low and mulling over vitality efficiency, particularly because of the presence of certain gadgets with exceptionally constrained vitality limit without simple access to charging choices.

\section{Related Work}

In outlining the little cell arrangements for HetNets, versatile administrators run over two significant issues as to move traffic from little cell at the corner profoundly of the portable system and to access with the radio access arrange, exactly, obstruction what's more, asset administration. Be that as it may, these are two isolate looks into issues that are firmly coupled, on the grounds that to a specific degree how the system oversees traffic dispersion defines the systems the administrator can effectively use to decrease and arrange impedance. The edge connects that interfaces little cells to whatever is left of the system may utilize distinctive advances: wired or remote. mmWave has just been institutionalized for less range administrations, for example, little cell backhauls. In this manner, it prompts unequalled information rates and a totally diverse client encounter if conveyed for appropriation.

When utilizing a backhaul design, an incorporated little cell is associated with a collection point. A large-scale cell area is associated. As those cell forms the Random-Access Network activity, the administrator can utilize numerous answers for backhaul, which includes fibre and wireline innovations, remote connections Remote connections may incorporate LOS or NLOS groups; point towards guide, points toward multi point; and authorized permit excluded groups. The underscore, the arrangement of organize administrators' utilization in the present systems to convey information administrations requiring little to no effort. For this "framework based" multi-level arrangement, the cell overlays 
organize misuses the backhaul administration for conveying fast administrations at moderately minimal effort, while the normal large-scale cell organize keeps on conveying standard lower information rate benefits over wide range coverage.

On a more extensive viewpoint, the partition permits new courses for sharing foundations possessed and sent by various administrators; that can be overseen/worked by the control plane as per the particular arrangement of business governs under a typical understanding. In the imagined situation, the control and information plane are first part. The full-scale Base Station demonstrates flagging administration to entire territory and these have versatile little cells specific to conveying information administrations for maximum transmission rate with low control overhead and proper air interface.

\section{Simulation Results}

We evaluated non-power aware of 5G networks in virtual machine with cloud sim and netbeans. At different hosts and virtual machine, we have obtained the power utilization of each host. The utilization is shown in the tabular forms below.

\begin{tabular}{|c|c|c|c|}
\hline Host & VM & MIPS & Utilization \\
\hline 0 & 0 & & 0 \\
\hline \multirow[t]{3}{*}{1} & 15 & 824.74 & 82.4 \\
\hline & 16 & 147.7 & 58.9 \\
\hline & 17 & 214.5 & 42.9 \\
\hline \multirow[t]{6}{*}{2} & 0 & 186.74 & 74.69 \\
\hline & 1 & 483.45 & 96.69 \\
\hline & 2 & 379.42 & 50.59 \\
\hline & 3 & 363.36 & 36.34 \\
\hline & 4 & 141.38 & 56.55 \\
\hline & 8 & 167.3 & 66.92 \\
\hline 3 & 0 & & 0 \\
\hline \multirow[t]{2}{*}{4} & 18 & 605.31 & 80.71 \\
\hline & 19 & 116.85 & 11.68 \\
\hline \multirow[t]{5}{*}{5} & 5 & 188.87 & 37.77 \\
\hline & 6 & 562.43 & 74.99 \\
\hline & 7 & 862.11 & 86.21 \\
\hline & 9 & 1.06 & 0.21 \\
\hline & 12 & 83.25 & 33.3 \\
\hline 6 & 0 & & 0 \\
\hline 7 & 0 & & 0 \\
\hline \multirow[t]{4}{*}{8} & 10 & 583.02 & 77.74 \\
\hline & 11 & 892.19 & 89.22 \\
\hline & 13 & 199.82 & 39.96 \\
\hline & 14 & 526.06 & 70.14 \\
\hline 9 & 0 & & 0 \\
\hline
\end{tabular}

From the above table the average power utilized by the all hosts is 56.3965 Watts.

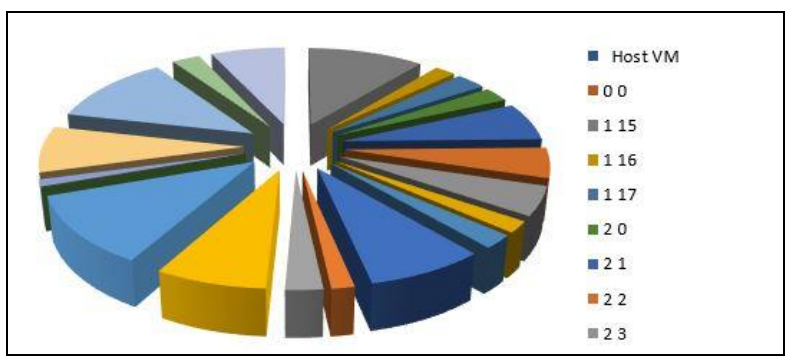

Power Utilization of different hosts at time $=5$ seconds with respect to different virtual machines.

Table 2 At Time $=10$ Seconds

\begin{tabular}{|l|l|l|l|}
\multicolumn{4}{|c|}{ Table 2 At Time $=10$ Seconds } \\
\hline Host & VM & MIPS & Utilization \\
\hline 1 & 15 & 518 & 51.8 \\
\hline & 16 & 137.95 & 55.18 \\
\hline & 17 & 443.05 & 88.61 \\
\hline 2 & 0 & 220.4 & 88.16 \\
\hline & 1 & 152.89 & 30.58 \\
\hline
\end{tabular}

\begin{tabular}{|c|c|c|c|}
\hline & 2 & 242.03 & 32.27 \\
\hline & 3 & 802.46 & 80.25 \\
\hline & 4 & 99.38 & 39.75 \\
\hline & 8 & 215.24 & 86.1 \\
\hline 3 & 0 & & 0 \\
\hline \multirow[t]{2}{*}{4} & 18 & 600.33 & 80.04 \\
\hline & 19 & 823.6 & 82.36 \\
\hline \multirow[t]{5}{*}{5} & 5 & 375.4 & 75.08 \\
\hline & 6 & 51.02 & 6.8 \\
\hline & 7 & 503.56 & 50.36 \\
\hline & 9 & 262.78 & 52.56 \\
\hline & 12 & 31.22 & 12.49 \\
\hline 6 & 0 & & 0 \\
\hline 7 & 0 & & 0 \\
\hline \multirow[t]{4}{*}{8} & 10 & 269.61 & 35.95 \\
\hline & 11 & 795.08 & 79.51 \\
\hline & 13 & 18.75 & 3.75 \\
\hline & 14 & 730.54 & 97.4 \\
\hline 9 & 0 & & 0 \\
\hline
\end{tabular}

From the above table the average power utilized by the all hosts is 47.04167 Watts.

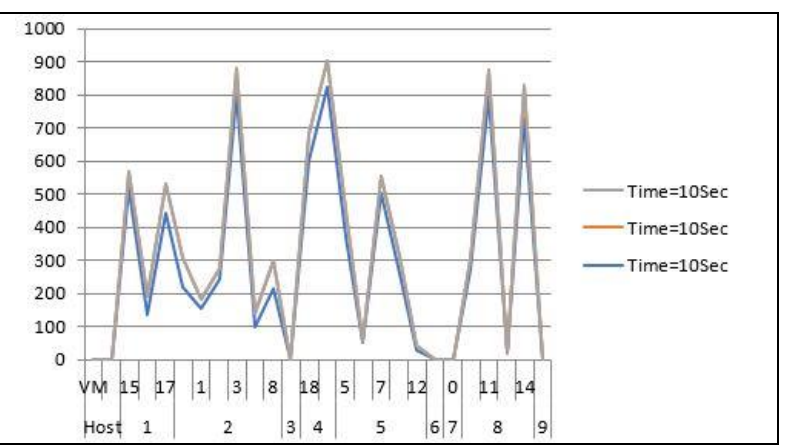

Power Utilization of different hosts at time $=10$ seconds with respect to different virtual machines.

Table 3 At Time $=15$ Seconds

\begin{tabular}{|c|c|c|c|}
\hline Host & VM & MIPS & Utilization \\
\hline 0 & 0 & & 0 \\
\hline \multirow[t]{3}{*}{1} & 15 & 646.83 & 64.68 \\
\hline & 16 & 217.13 & 86.85 \\
\hline & 17 & 306.38 & 61.28 \\
\hline \multirow[t]{6}{*}{2} & 0 & 118.01 & 47.2 \\
\hline & 1 & 94.98 & 19 \\
\hline & 2 & 391.96 & 52.26 \\
\hline & 3 & 356 & 35.6 \\
\hline & 4 & 160.95 & 64.38 \\
\hline & 8 & 100.65 & 40.26 \\
\hline 3 & 0 & & 0 \\
\hline \multirow[t]{2}{*}{4} & 18 & 468.38 & 62.45 \\
\hline & 19 & 403.97 & 40.4 \\
\hline \multirow[t]{5}{*}{5} & 5 & 379.59 & 75.92 \\
\hline & 6 & 265.62 & 35.42 \\
\hline & 7 & 745.18 & 74.52 \\
\hline & 9 & 286.16 & 57.23 \\
\hline & 12 & 56.99 & 22.8 \\
\hline 6 & 0 & & 0 \\
\hline 7 & 0 & & 0 \\
\hline \multirow[t]{4}{*}{8} & 10 & 485.81 & 64.78 \\
\hline & 11 & 439.39 & 43.94 \\
\hline & 13 & 426.83 & 85.37 \\
\hline & 14 & 602.71 & 80.36 \\
\hline 9 & 0 & & 0 \\
\hline
\end{tabular}

From the above table the average power utilized by the all hosts is 44.588 Watts. 


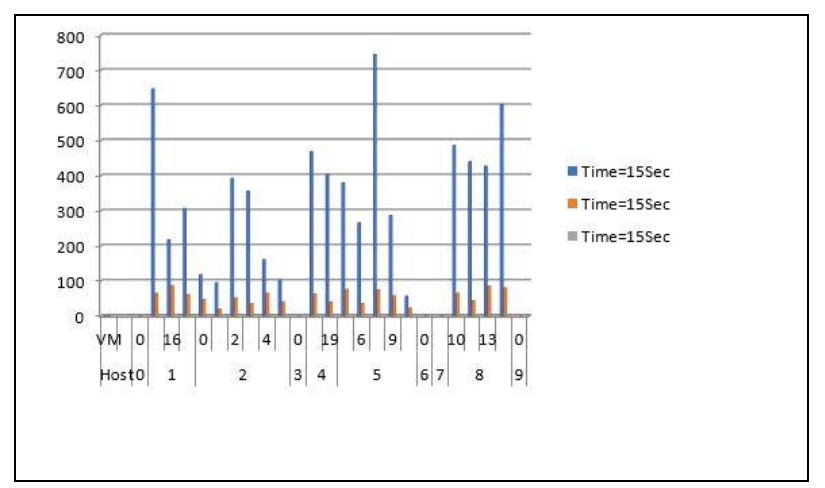

Power Utilization of different hosts at time $=15$ seconds with respect to different virtual machines.

Table 4 At Time $=20$ Seconds

\begin{tabular}{|c|c|c|c|}
\hline Host & VM & MIPS & Utilization \\
\hline 0 & 0 & & 0 \\
\hline \multirow[t]{3}{*}{1} & 15 & 428.17 & 42.82 \\
\hline & 16 & 9.57 & 3.83 \\
\hline & 17 & 90.01 & 18 \\
\hline \multirow[t]{6}{*}{2} & 0 & 93.95 & 37.58 \\
\hline & 1 & 253.3 & 50.66 \\
\hline & 2 & 468.39 & 62.45 \\
\hline & 3 & 547.39 & 54.4 \\
\hline & 4 & 3.27 & 1.31 \\
\hline & 8 & 243.82 & 97.53 \\
\hline 3 & 0 & & 0 \\
\hline \multirow[t]{2}{*}{4} & 18 & 50.75 & 6.77 \\
\hline & 19 & 941.24 & 94.12 \\
\hline \multirow[t]{5}{*}{5} & 5 & 100.84 & 20.17 \\
\hline & 6 & 172.35 & 22.98 \\
\hline & 7 & 612.2 & 61.22 \\
\hline & 9 & 249.22 & 49.84 \\
\hline & 12 & 104.95 & 41.98 \\
\hline 6 & 0 & & 0 \\
\hline 7 & 0 & & 0 \\
\hline \multirow[t]{4}{*}{8} & 10 & 12.89 & 1.72 \\
\hline & 11 & 530.31 & 53.03 \\
\hline & 13 & 497.38 & 99.48 \\
\hline & 14 & 213.85 & 28.51 \\
\hline 9 & 0 & & 0 \\
\hline
\end{tabular}

From the above table the average power utilized by the all hosts is 33.936 Watts.

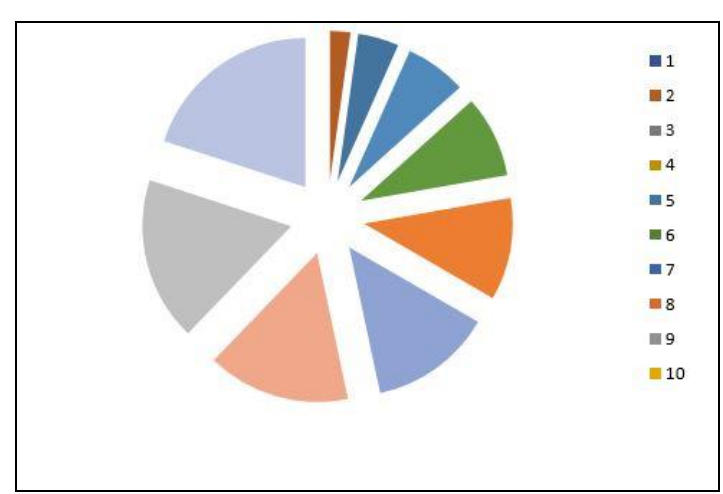

Power Utilization of different hosts at time $=20$ seconds with respect to different virtual machines.

\section{Conclusion}

Versatile traffic and the utilization of advanced broadband administrations, alongside the foreseen increment in the number of versatile gadgets. Increasing developments are not predicted to encounter the prerequisites of portable systems. Thus, examination endeavours currently coordinated to Fifth Generation. In this paper, we talk about an ease arrangement based on innovations that are generally acknowledged to keep on existing inside the Fifth-
Generation worldview. Later, we simulated provisioning of non power aware virtual machines for real time services of cloud. Results present that datacentres can decrease power consumed by them hence they the benefit of data centres is increased. The proposed adaptive schemes demonstrate more benefit with lesser power utilization irrespective of load applied by the system.

\section{References}

[1] The Amazon Cloud Compute

[2] M. Armbrust, et al. over the Clouds: A Berkeley vision of cloud computing. Technology.

[3] Energy efficient cmos microprocessor design. In Proc. of Annual Hawaii International Conference January 1995.

[4] Challenges and opportunitie. In Proc. of the 7th High Performance Computing and Simulation (HPCS 2009). Leipzig, Germany, June 2009.

[5] Shares and utilities based power consolidation in virtualized server environments. In Proc. of IFIP/IEEE Intl.

[6] Overseeing vitality and server assets in facilitating focuses. In Procedure of 8th ACM Operating Systems values.

[7] X. A. Feng and A. K. Mok. A model of hierarchical real-time virtual resources, Dec. 2002.

[8] A. Gandhi, M. Harchol-Balter, R. Das, and C. Lefurgy. Optimal power allocation in server farms. In Proc. of Intl. Joint Conf. on Measurement and Modeling of Computer Systems, June 2009.

[9] R. Ge, X. Feng, and K. W. Cameron. Performance-constrained distributed DVS scheduling for scientific applications on poweraware clusters, November 2005.

[10] C. Hsu and W. Feng. A power-aware run-time system for highperformance computing, November 2005.

[11] N. Kappiah, V. W. Freeh, and D. K. Lowenthal. Just in time dynamic voltage scaling: Exploiting inter-node slack to save energy in MPI programs, November 2005.

[12] K. H. Kim, R. Buyya, and J. Kim. Power aware scheduling of bag-of-tasks applications with deadline constraints on DVSenabled clusters, May 2007.

[13] KISHORE, P.V.V., KISHORE, S.R.C. and PRASAD, M.V.D., 2013. Conglomeration of hand shapes and texture information for recognizing gestures of indian sign language using feed forward neural networks. International Journal of Engineering and Technology, 5(5), pp. 3742-3756.

[14] LAKSHMI, M.L.S.N.S., KHAN, H. and MADHAV, B.T.P., 2015. Novel sequential rotated $2 \times 2$ array notched circular patch antenna. Journal of Engineering Science and Technology Review, 8(4), pp. 73-77.

[15] MADHAV, B.T.P., KAZA, H., VAKA, J.K., SRAVAN KUMAR, K., SRIHARSHA, N., JASWANTH KUMAR, J., SIDDHARTH, D.S. and SAI TEJA REDDY, D., 2015. Design and analysis of compact coplanar wave guide fed asymmetric monopole antennas. Research Journal of Applied Sciences, Engineering and Technology, 10(3), pp. 247-252.

[16] MADHAV, B.T.P., KHAN, H. and KOTAMRAJU, S.K., 2016. Circularly polarized slotted aperture antenna with coplanar waveguide fed for broadband applications. Journal of Engineering Science and Technology, 11(2), pp. 267-277.

[17] KISHORE, P.V.V., SASTRY, A.S.C.S. and KARTHEEK, A., 2014. Visual-verbal machine interpreter for sign language recognition under versatile video backgrounds, 1st International Conference on Networks and Soft Computing, ICNSC 2014 - Proceedings 2014, pp. 135-140.

[18] KARTHIK, G.V.S., FATHIMA, S.Y., RAHMAN, M.Z.U., AHAMED, S.R. and LAY-EKUAKILLE, A., 2013. Efficient signal conditioning techniques for brain activity in remote health monitoring network. IEEE Sensors Journal, 13(9), pp. 3273-3283.

[19] KILARU, S., HARIKISHORE, K., SRAVANI, T., ANVESH CHOWDARY, L. and BALAJI, T., 2014. Review and analysis of promising technologies with respect to Fifth generation networks, 1st International Conference on Networks and Soft Computing, ICNSC 2014 - Proceedings 2014, pp. 248-251.

[20] Sastry, J.K.R., Ganesh, J.V., Bhanu, J.S., I2C based networking for implementing heterogeneous microcontroller based distributed embedded systems, Indian Journal of Science and Technology, Volume 8, Issue 15, 2015 